\title{
Resettlement and Reintegration: Single Mother's Reflections after Homelessness
}

\author{
Victoria Tischler \\ University of Nottingham, UK
}

Victoria Tischler, Division of Psychiatry- Behavioural Sciences. A Floor, South Block, Queens Medical Centre. Nottingham. NG7 2UH. UK

Telephone: +44 (0115) 8230412, Fax: +44 (0115) 8230433

victoria.tischler@nottingham.ac.uk

(word count: 3505 excluding references) 


\section{Resettlement and reintegration: Single Mother's Reflections after homelessness}

\section{Abstract}

Previous research has identified that most families who become homeless are women with dependent children. Homeless families are reported to have a variety of complex needs however little is known about the experiences of families once they are re-housed. The aim of this study was to explore psychosocial issues related to the resettlement experiences of single mothers following a period of homelessness. Qualitative semi-structured interviews were used to gather data from twenty one women living in a UK Midlands city. Thematic analysis was used to draw conclusions from the data. Findings indicated that despite exposure to major stressors most women had begun the process of resettlement by improving their physical surroundings. Women had achieved personal growth as they had managed to escape violence, overcome homelessness, and create new opportunities for themselves and their children. Suggestions are made for future research and improvements to services which would promote resettlement in this population.

Keywords

adaptation, homelessness, mothers, reintegration, resettlement 


\section{Resettlement and reintegration: Single Mother's Reflections after homelessness}

\section{Introduction}

Family homelessness is a major social problem. Previous research regarding the characteristics of homeless families has found a history of adversity (e.g. Bassuk et al, 1997; Bassuk et al, 2001), mental health problems among mothers and children (Vostanis et al, 1998; Anooshian, 2005), and limited access to services (Cumella et $a l, 1998)$. Very little attention has been given to the experiences of families following their exit from homelessness. The current study focuses on psychosocial issues related to homelessness and resettlement as much previous UK research in this field has concentrated on structural issues such as housing policy (Christian, 2003).

Substantial numbers of families experience homelessness in the UK and worldwide. Families as a proportion of the total homeless population comprise $41 \%$ in the United States and $49 \%$ in Britain (US Conference of Mayors, 2002; Office of the Deputy Prime Minister, 2004). Overwhelmingly, homeless families are women with dependent children who are roofless or who live in unstable or temporary accommodation, most of whom are fleeing domestic violence or relationship breakdown (e.g. Vostanis et al, 1998). The majority of these women conform to Schein's (1982) 'ABC' factors 
which characterise economically poor single mothers. ' $A$ ' represents the absence of education and training, ' $\mathrm{B}$ ' denotes betrayal by a partner and ' $C$ ' refers to negative childhood experiences. Schein argues that factors ' $A$ ' and ' $\mathrm{B}$ ' precipitate a single mother's decline into poverty and ' $\mathrm{C}$ ' undermines her efforts to escape from poverty.

Recent UK figures show a year on year increase in the number of homeless families: 39, 810 in 2002, 53, 070 in 2003, and 64, 340 in 2004 (Department of Work and Pensions, 2004). Latest figures report that 69790 homeless households contained children and/or a pregnant woman (National Statistics, 2006). Others suggest that the official figures are underestimates and that 100000 families are currently homelessness in the UK (Woods, 2006).

What is already known about Family Homelessness?

Homelessness arises through a combination of structural and individual factors. Structural factors include the lack of low-cost housing (e.g. Stojanovic et al, 1999) and individual factors include time spent in care (e.g. Bassuk et al, 1997). Homelessness is acknowledged to be a stressor (Goodman, 1991). Whilst a number of studies have examined the characteristics of homeless women and children (e.g. Bassuk et al, 1996) and narrative descriptions of homelessness (Banyard, 1995), the experiences of resettlement and reintegration into the community have largely been neglected. This 
is important as women who have childhood experiences of violence, sexual abuse or experience of partner violence following re-housing are at risk of repeated homelessness (Bassuk et al, 2001).

One qualitative study was identified which explored the life histories of formerly homeless single mothers. The findings indicated that the loss of home represented a turning point for many respondents and that specialist services were needed to address the multiple difficulties that these women face whilst homeless and afterwards (Styron et al, 2000). These findings suggest that mothers experiencing homelessness have needs that persist after re-housing and that resettlement is a long term process.

\section{Resettlement}

Resettlement includes a number of proximal components; permanent accommodation, house-keeping skills, and a subjective sense about whether people are in the right place (Rivlin and Moore, 2001). These factors emanate from a person's concept of 'home' (Moore, 2000a) which has been described as a fluid construct that relates not only to a physical structure, but to a process which is closely aligned with a person's sense of personal growth (Horwitz and Tognoli, 1982). Further, housing that promotes factors such as independence, control and privacy can contribute to positive well-being (Moore, 2000b) including reintegration into the 
wider community. As Shrubsole states, housing provides "roots, identity, security, a sense of belonging and emotional wellbeing" (Shrubsole, in Riddell, 2006, p. 1). The sense of home as a place of safety and security will be absent for many women experiencing homelessness after fleeing violence (Tomas \& Dittmar, 1995). The importance of providing secure housing for women and children escaping violence has been identified as a key factor in helping them rebuild their lives (Malos \& Hague, 1997).

A sense of home may relate to the wider context of community. This is characterised by factors such as shared identity and common activities (Fulcher \& Scott, 2003). Communities may also develop neighbourhood features. This occurs when individuals within the community exhibit 'giving' and 'sharing' behaviours (Doyle, 1992) such as inviting neighbours to visit, thus providing opportunities for social networking. Integration in these contexts may be more difficult for previously homeless families who can be placed in the worst accommodation on marginalized estates due to the limited social housing stock available (Collard, 1997). Women escaping violence may also be moved to a geographical area far from their previous home potentially isolating them from support networks. This suggests that homelessness and resettlement are not simply housing problems but involve often complex interactions between individual, social and economic factors (Taylor-Gaubatz, 2001) thus 
recommending an ecological approach to investigation (Toro et al, 1991).

A number of micro and macro factors influence resettlement. Some authors, for example, Lindsey (1998) stress the importance of psychological resources, such as the motivation and attitude of homeless mothers in achieving re-housing. Others argue that the housing stability is promoted by the availability of affordable, good quality accommodation (Shinn, 1997). This is aligned with the Government's promotion of sustainable communities which should contain 'decent, affordable' housing (Communities and Local Government, 2006). Housing is only one component of resettlement. Economic factors such as employment strategies are also critical according to Shinn et al (2001). Rivlin and Moore (2001) argue that in addition to permanent accommodation, quality of life and lifestyle must be promoted. This includes diverse variables such as social support, security, comfort and cultural requirements which aid reintegration. Studies examining resettlement in US formerly homeless populations suggest that it is a long-term process, often hampered by lack of resources, such as finance and education (Dunlap \& Fogel, 1998; Rog, 1999).

Resettlement services which target both accommodation and support needs (Seddon, 1997; Tischler, 2002) are increasingly 
being used to assist vulnerable individuals who struggle to maintain their tenancies. In the US, 'housing plus' services have been established to promote resettlement. These integrate housing and services to enhance social and economic well-being (Cohen et al, 2004). Other programmes have moved families into more prosperous neighbourhoods where respondents report psychological improvements such as an increased sense of self efficacy (Rosenbaum et al, 2002). Such services are yet to be widely developed in the UK although there is some evidence that provision such as Shelter's 'Homeless to Home' can help to sustain tenancies (Jones et al, 2002). Research identifying the experiences of resettling families and their needs relating to that process will inform further development of appropriate services for this population.

\section{Aims of the study}

This study aimed to investigate the experience of resettlement in a group of single mothers with dependent children who had experienced homelessness. A number of issues related to resettlement were explored. These were: satisfaction with new accommodation, their feelings about their home compared to their feelings whilst homeless, what they had learnt from their experiences of homelessness, and their hopes for the future. 
Method

The 21 participants were drawn from a wider, longitudinal study of family homelessness, the results of which are reported elsewhere (Tischler et al, 2002; Tischler \& Vostanis, in press). The women had been recruited consecutively over a period of 12 months from 3 Local Authority managed hostels for homeless families and had agreed to be interviewed again at four month follow-up. Of the 44 families traced at follow-up, 21 single mothers agreed to discuss their experiences in more detail. Families headed by single fathers or couples were excluded from the analyses as evidence from other studies indicates that these family-structures become homeless for different reasons, for example eviction (Vostanis et al, 2001), compared to single mothers whose reason for loss of home is usually domestic violence. It was also hypothesised that single mothers would have different needs and resources available compared to adults in alternate family-structures.

All participants were interviewed by the author in their homes following resettlement. A qualitative, semi-structured questionnaire gathered reflections on the period of homelessness, feelings about their new living arrangements, and explored respondents' hopes for the future. This method includes open-ended questions which allow respondents to reply in their own words and to raise other relevant issues (Carter \& Henderson, 2005). Qualitative research has been 
used previously to investigate sensitive issues including the experiences of single mothers living in poverty (e.g. Brodsky, 1999) and to understand the phenomenon of domestic violence from women's perspectives (e.g. Lutenbacher et al, 2003). Such methodologies have been noted to help validate women's experiences and hence promote empowerment (Davis, 2002). The transcripts were analysed using thematic analysis. This is an inductive process which involves systematically extracting and counting themes from the data (Joffe and Yardley, 2004). Demographic information was also collected from participants, including views on satisfaction with their new homes.

\section{Characteristics of participants}

The participants were single mothers with a median age of 35 years, and one or more dependent children (median: 2, range 1-6). Almost half $(10,47.6 \%)$ were of White UK ethnicity, $6(28.6 \%)$ were British Afro-Caribbean, 4 (19\%) were British Asian and 1 $(4.8 \%)$ was White Irish. The majority were homeless as a result of domestic violence at the hands of a male partner $(16,76.2 \%)$ or harassment by neighbours $(3,14.3 \%)$. All had been previously housed in temporary accommodation by a Local Authority in the West Midlands after being accepted as statutorily homeless ${ }^{1}$. New homes were either Local Authority council housing or Housing

\footnotetext{
${ }^{1}$ According to the 1996 Housing Act
} 
Association properties. No data was collected on the length of stay at current address although most families had been re-housed for a short period of time, usually a few weeks.

\section{Resettlement}

All participants were re-housed with a permanent tenancy. Data revealed some ambivalence regarding satisfaction with their new home. Eight (38.1\%) stated that they were satisfied, 6 (28.6\%) were not and 7 (33.3\%) expressed uncertainty. Ambivalence was related to the accommodation itself, concerns about the environment, and little choice over housing that they were offered as the excerpts below reveal:

The area is quiet. I am not happy to be here but I had no choice, I felt obliged, pressured to take this property (36 year old mother of 2 )

I don't like it [accommodation] as the area is not safe, I don't feel safe here, the locals are rough. The kids are happy to be here though (33 year old mother of 3 )

The area has a bad reputation, it is worse than it actually is, it's still not nice, there are problems with drugs and in the past, riots. I am happy to be here, I like my house and the 
back area is secure for the children to play ( 29 year old mother of 2)

Despite these concerns women often described their circumstances favourably compared to the homeless period and focussed on positive outcomes such as improvements in mental health and children attending school as the following extracts reveal.

I feel better now than when I was homeless. At the hostel I felt pretty low because of all the rules and having to manage the children confined within four walls (34 year old mother of 5)

I have my own place so I can do what I want, when I want. There is nobody watching you, I hated those cameras at the hostel, it felt like you were being watched ( 25 year old mother of 1 )

Now I've got things to do in the house, decorating and stuff, I'm constantly doing something. In the hostel I just sat there waiting. (30 year old mother of 3 )

Respondents' were asked to reflect on what they had learnt from being homeless. Three major themes were identified. These were 
escaping violence, improving the system, and opportunities for growth.

Most respondents stated that escaping violence had been the most important outcome of the time spent homeless. This included leaving a violent partner or escaping from violent or harassing neighbours. A number suggested that they would strongly advise other women to leave violent partners in order to protect themselves and their children as the excerpt below illustrates.

Come out of a violent relationship, it's hard but it's worth it and there is hope (41 year old mother of 2 )

Many respondents were keen to see the homeless system improve. They were critical of the conditions in the hostels, poor treatment by staff, and the lack of facilities for children. A number of suggestions were made regarding improvements to hostel environments and the experience of homelessness. The services most sought after were counselling, practical support for parents, and childcare and play facilities for children as the extracts below reveal. 
There needs to be someone coming into the hostel to support and counsel women, and to help them gain self-respect (39 year old mother of 2 )

It [hostel] should provide better facilities, like child care for kids not in school. They should help you get kids into school and offer more opportunities for kids to play (43 year old mother of 3)

Following resettlement a number of respondents recognised that homelessness had offered them an important opportunity for personal growth. They identified personal achievements such as recognition of inner strength, the ability to seek help independently, and helping others. Some reframed their predicament and many expressed feelings of liberation and freedom. As one participant stated:

I learnt that there are people worse off than me, this makes me feel stronger. When I see homeless people on the streets, I know how they feel (41 year old mother of 2)

Finally, respondents were asked what their hopes were for the future. The hopes described by respondents were straightforward and realistic and the key themes identified were stability and 
wishing for a better life. This involved a variety of outcomes such as, a stable home, happiness for themselves and their children, education for their children, and employment, education and training for themselves. As one woman described:

I just want to get settled with the kids. To get a nice big house and settle down without any hassle. We just want a bit of peace. (37-year-old mother of 4)

\section{Conclusions}

This exploratory study provides insights into the experiences of formerly homeless single mothers and the process of resettlement in this population. No other UK studies which have examined these issues were identified. Despite enduring serious trauma prior to losing their homes and the adversity associated with homelessness most women were able to reflect positively on their new circumstances. This supports findings in other studies of economically poor, single mothers (Brodsky, 1999) and indicates resourcefulness and resilience in this population.

Despite ambivalence about their new accommodation, most women described their circumstances favourably compared to the time they had spent homeless. Outcomes of homelessness were positive overall with women focussing on change at both micro and macro 
levels. Women described feeling a sense of freedom and independence compared to the confined conditions in the homeless hostels. Many women had achieved personal growth and a new sense of mastery as they had overcome homelessness and escaped from violence thus creating a new life for themselves and their children. This supports previous qualitative findings in this population which suggest that homelessness can be a respite from previous traumas (Styron et al, 2001) and can help to improve skills, for example parenting (Kissman, 1999). The findings also support the concept of 'posttraumatic growth' which suggests that individuals can experience positive changes after experiencing traumatic events (Tedeschi \& Calhoun, 2004). Despite these positive outcomes, many women were fiercely critical about the lack of resources available whilst homeless and suggested that system change was required, for example that services such as counselling should be made available in hostels.

It was not possible to establish that these women had resettled according to definitions which emphasise security, a sense of 'home' and integration into the wider community. The data did however confirm that the process of resettlement had begun as most of the women indicated that they had achieved independence and that they were starting to plan for the future by settling children in local schools and considering educational and employment opportunities 
for themselves. This supports other findings in this population which emphasise the long-term nature of the resettlement process (Rog, 1999).

Many respondents raised concerns about the quality of the housing, deprivation and crime in the area to which they had moved. It was evident that women had made compromises in order to escape from homelessness, such as accepting a house in an undesirable area. This supports the findings of Collard (1997) regarding the poor housing stock that may be offered to families who have been homeless. Other findings suggest that women living in deprived or crime-ridden areas may make a positive choice not to get involved with neighbours (Brodsky, 1996). These factors may inhibit a family's reintegration into a community and their ability to feel safe and secure.

None of the participants were receiving resettlement or other specialist support to maintain their tenancy and to help them integrate with their new communities. Given the ambivalence expressed regarding housing and the surrounding environment, the risk of future housing instability seems high. Development of services to address tenancy and support needs is recommended given the risks of repeated homelessness, (Bassuk et al, 2001) and other findings stressing the importance of follow-up in this 
population (Walters \& East, 2001). Improvements to the services available to families in hostels are also warranted, such as provision of counselling and child care. These would build skills and resources in families and help them prepare for resettlement. Services could be based upon successful models developed in the United States such as 'Housing Plus' provision (Cohen et al, 2004).

The study had some limitations. Participants were interviewed soon following re-housing and this may have been insufficient time in which to establish whether resettlement had occurred. If the women were visited after they had been resident in their new homes for a longer period they may have reported outcomes related to resettlement such as making new friends in the area or gaining employment. Alternatively, they may have moved on due to dissatisfaction with their housing or further experiences of violence or harassment.

This research included women who had approached the Local Authority Housing Department for help. It has been suggested that women who utilise hostel services are 'help-seekers' (Waldrop \& Resick, 2004) and therefore may not be representative of all mothers experiencing homelessness. The research focussed on mothers experiences. Thus the views of children may have been neglected although mothers reported that children were beginning 
to resettle, for example, by attending school in the area. The study was however exploratory in nature and thus aimed to uncover key issues and to gather insights about an under-researched phenomenon (Dyer, 2006). In addition the use of qualitative data gives voice to a marginalised group of women who may be referred to as a 'hidden homeless' population.

Future research should incorporate the views of formerly homeless children as other studies have reported that children are able to appraise their environment, for example, the value of neighbourhood places such as designated play areas (Min \& Lee, 2006). This would provide useful information related to family functioning in addition to the mother's perceptions of resettlement which were the focus of the current study.

Future research could also examine how race impacts on the process of resettlement. Previous studies have reported that cultural factors impact on women's experiences of domestic violence (e.g. Kumar et al, 2005). Cultural and gender issues may also impact on resettlement. For example, seeking social support has been reported to be an important form of coping for those from non-Western backgrounds (Aldwin, 1994) and for women (e.g. Felsten, 1998). 
Future longitudinal studies should investigate whether resettlement is successful in the longer-term in this population and in other families who become homeless. Finally resettlement services should be evaluated in order to develop a model that effectively promotes the long term stability and welfare of these vulnerable families.

\section{Acknowledgements}

Sincere thanks to all the women who shared their stories with me. 
Aldwin, C. M. (1994). Stress, Coping and Development. An Integrative Approach. New York, Guilford Press.

Anooshian, L. J. (2005). "Violence and aggression in the lives of homeless children." Journal of Family Violence 20(6): 373387.

Banyard, V. L. (1995). "'Taking another route": Daily survival narratives from mothers who are homeless." American Journal of Community Psychology 23(6): 871-891.

Bassuk, E. L., J. C. Buckner, et al. (1997). "Homelessness in female-headed families: Childhood and adult risk and protective factors." American Journal of Public Health 87(2): 241-248.

Bassuk, E. L., J. N. Perloff, et al. (2001). "Multiply homeless families: The insidious impact of violence." Housing Policy Debate 12(2): 299-320.

Bassuk, E. L., L. F. Weinreb, et al. (1996). "The characteristics and needs of sheltered homeless and low-income housed mothers." Jama-Journal of the American Medical Association 276(8): 640-646.

Brodsky, A. E. (1996). "Resilient single mothers in risky neighborhoods: Negative psychological sense of community." Journal of Community Psychology 24(4): 347-363.

Brodsky, A. E. (1999). "'Making it": The components and process of resilience among urban, African-American, single mothers." American Journal of Orthopsychiatry 69(2): 148-160.

Carter, S. and L. Henderson (2005). Approaches to qualitative data collectionin social science. Handbook of Health Research Methods: Investigation, Measurement and Analysis

A. Bowling and S. Ebrahim. Berkshire, Open University Press: 215-229.

Christian, J. (2003). "Homelessness: Integrating international perspectives - Introduction." Journal of Community \& Applied Social Psychology 13(2): 85-90.

Cohen, C. S., E. Mulroy, et al. (2004). "Housing Plus services: Supporting vulnerable families in permanent housing." Child Welfare 83(5): 509-528.

Collard, A. (1997). Settling Up. Towards a Strategy for Resettling Homeless Families. London, London Homelessness Forum.

Communities and Local Government (2006). "What is a sustainable community?" Retrieved 4th December, 2006, from http://www.communities.gov.uk/index.asp?id=1139866.

Cumella, S., E. Grattan, et al. (1998). "The mental health of children in homeless families and their contact with health, education and social services." Health \& Social Care in the Community 6(5): 331-342. 
Doyle, K. (1992). "The Symbolic Meaning of House and Home - an Exploration in the Psychology of Goods." American Behavioral Scientist 35(6): 790-802.

Dunlap, K. M. and S. J. Fogel (1998). "A preliminary analysis of research on recovery from homelessness." Journal of Social Distress and the Homeless 7(3): 175-188.

Dyer, C. (2006). Research in Psychology. A practical guide to methods and statistics. Oxford, Blackwell.

Felsten, G. (1998). "Gender and coping: Use of distinct strategies and associations with stress and depression." Anxiety Stress and Coping 11(4): 289-309.

Fulcher, J. and J. Scott (2003). Sociology. Oxford, Oxford University Press.

Gaubatz, K. T. (2001). "Family Homelessness in Britain: More than just a housing issue." Journal of Children and Poverty 7(1): 322.

Goodman, L., L. Saxe, et al. (1991). "Homelessness as Psychological Trauma - Broadening Perspectives." American Psychologist 46(11): 1219-1225.

Horwitz, J. and J. Tognoli (1982). "Role of Home in Adult Development - Women and Men Living Alone Describe Their Residential Histories." Family Relations 31(3): 335-341.

Joffe, H. and L. Yardley (2004). Content and Thematic Analysis. Research Methods for Clinical and Health Psychology. D. Marks and L. Yardley (pp. 56-68). London, Sage.

Jones, A., Pleace, N., Quilgars, D. (2002). Firm Foundations: An Evaluation of the Shelter Home to Home Service. London, Shelter.

Kissman, K. (1999). "Respite from stress and other service needs of homeless families." Community Mental Health Journal 35(3): 241-249.

Kumar, S., L. Jeyaseelan, et al. (2005). "Domestic violence and its mental health correlates in Indian women." $\mathrm{Br}$ J Psychiatry 187(1): 62-67.

Lindsey, E. W. (1998). "Service providers' perception of factors that help or hinder homeless families." Families in Society-the Journal of Contemporary Human Services 79(2): 160-172.

Lutenbacher, M., A. Cohen, et al. (2003). "Do we really help? Perspectives of abused women." Public Health Nursing 20(1): 56-64.

Malos, E. and G. Hague (1997). "Women, housing, homelessness and domestic violence." Womens Studies International Forum 20(3): 397-409.

Min, B. and J. Lee (2006). "Children's neighborhood place as a psychological and behavioral domain." Journal of Environmental Psychology 26(1): 51-71.

Moore, J. (2000). "Health and Home for Homeless People in 
Transition." Reviews on Environmental Health 15(1-2): 207217.

Moore, J. (2000). "Placing home in context." Journal of Environmental Psychology 20(3): 207-217.

National Statistics (2004). "Housing Statistics." Retrieved 6th April 2005.

Office of the Deputy Prime Minister (2004). "Opportunity for All: indicators for children and young people."

Riddell, M. (2006). Forty years after Cathy Come Home... The Observer.

Rivlin, L. G. and J. Moore (2001). "Home-making: Supports and barriers to the process of home." Journal of Social Distress and the Homeless 10(4): 323-336.

Rog, D. J. (1999). "The evaluation of the Homeless Families Program." American Journal of Evaluation 20(3): 558-561.

Rosenbaum, J. E., L. Reynolds, et al. (2002). "How do places matter? The geography of opportunity, self-efficacy and a look inside the black box of residential mobility." Housing Studies 17(1): 71-82.

Schein, V. E. (1995). Working from the Margins: voices of mothers in poverty. New York, Ithaca.

Seddon, T. (1997). "The National Resettlement Project." Housing Review 46(6): 121.

Shinn, M. (1997). "Family homelessness: State or trait?" American Journal of Community Psychology 25(6): 755-766.

Shinn, M., J. Baumohl, et al. (2001). "The Prevention of Homelessness Revisited." Analyses of Social Issues and Public Policy 1(1): 95-127.

Stojanovic, D., B. C. Weitzman, et al. (1999). "Tracing the path out of homelessness: The housing patterns of families after exiting shelter." Journal of Community Psychology 27(2): 199-208.

Styron, T. H., R. Janoff-Bulman, et al. (2000). "'Please ask me how I am": Experiences of family homelessness in the context of single mothers' lives." Journal of Social Distress and the Homeless 9(2): 143-165.

Tedeschi, R. G. and L. G. Calhoun (2004). "Posttraumatic growth: Conceptual foundations and empirical evidence." Psychological Inquiry 15(1): 1-18.

Tischler, V. (2002). "A resettlement service for Homeless and Vulnerable Parents." Community Care(25-31 July).

Tischler, V. and P. Vostanis (in press). "Homeless Mothers: Is there a relationship between coping strategies, mental health and goal achievement?" Journal of Community and Applied Social Psychology.

Tischler, V., P. Vostanis, et al. (2002). "Evaluation of a mental health outreach service for homeless families." Archives of 
Disease in Childhood 86(3): 158-163.

Tomas, A. and H. Dittmar (1995). "The Experience of homeless women: An exploration of housing histories and the meaning of home." Housing Studies 10(4): 493-516.

Toro, P. A., E. J. Trickett, et al. (1991). "Homelessness in the United-States - an Ecological Perspective." American Psychologist 46(11): 1208-1218.

US Conference of Mayors (2002). "A Status Report on Hunger and Homelessness in America's cities " Retrieved 2nd December, 2006, from http://www.usmayors.org/.

Vostanis, P., E. Grattan, et al. (1998). "Mental health problems of homeless children and families: Longitudinal study." British Medical Journal 316(7135): 899-902.

Vostanis, P., V. Tischler, et al. (2001). "Mental health problems and social supports among homeless mothers and children victims of domestic and community violence." International Journal of Social Psychiatry 47(4): 30-40.

Waldrop, A. E. and P. A. Resick (2004). "Coping among adult female victims of domestic violence." Journal of Family Violence 19(5): 291-302.

Walters, S. and L. East (2001). "The cycle of homelessness in the lives of young mothers: the diagnostic phase of an action research project." Journal of Clinical Nursing 10(2): 171-179.

Woods, B. (2006). "Growing up Homeless." Retrieved 4th December, 2006, from http://news.bbc.co.uk/1/hi/magazine/6192154.stm. 